\title{
LA TEORÍA DEL AMOR EXPUESTA POR LOS PERSONAJES CALDERONIANOS (REPERCUSIONES EN EL LÉXICO LITERARIO)
}

\author{
José CARLOS DE TORRES \\ Instituto de la Lengua Española \\ CSIC. Madrid
}

El dramaturgo madrileño nos ha dejado una muy rica muestra de citas sobre el tema amoroso al pertenecer, por su generación, a una densa tradición dramática al respecto, enriquecida luego con su propia aportación ${ }^{1}$. Para el análisis lingüístico hay que recordar que sus personajes (los galanes y las damas con sus criados y doncellas en las comedias de enredo) recitan sus sentimientos en parlamentos variados, lo mismo extensos que en pocos versos. La lectura revela una amplia gama de caracteres en función de los argumentos que van a vivir: los enredos inverosímiles (¡qué arquitectura de interiores urbanos; qué naturaleza bravía o palaciega, y qué libertad artística para crear la sensación de los irreal a base de luces y tinieblas repentinas!); el lenguaje equívoco para distorsionar lo más natu-

\footnotetext{
1 La bibliografía lingüística sobre Calderón es bastante menos numerosa que la literaria. Recordemos imprescindiblemente algunos trabajos del prof. Hans Flasche y la obra magna, en colaboración con Gerd HofmanN, Konkordanz zu Calderón. Concordancia aplicada a las obras de Calderón con auxilio de una computadora electrónica. Hildesheim. Georg Olms Verlag. 1981-88, 5 tomos. En esta línea hay que citar el muy útil TESO (incluye a más autores). Y el trabajo de Rafael Lapesa, por ejemplo («Lenguaje y estilo de Calderón», en CACIC, I, 1983, pp. 51-101). Las ediciones mejores de las obras calderonianas ofrecen notas sobre la lengua, pero hasta que no haya un estudio de conjunto, este aspecto lingüístico no podrá estar bien estudiado, además de su relación con otros dramaturgos. Por lo que he investigado, los lopistas no descuidan los estudios de la lengua. Basta recordar en la bibliografía más reciente los trabajos siguientes: M. a AZucena PenAs, «El lenguaje dramático de Lope de Vega». Anejo 16 del Anuario de Estudios Filológicos de la Universidad de Extremadura. 1996, 300 pp. Carlos SÁNCHEZ LANCIS, «La información lingüística diacrónica en la edición de la Parte Primera de las comedias de Lope de Vega», en Anuario Lope de Vega IV. Lleida. 1998, pp. 311-326. José Roso DíAz, «Las palabras del enredo. El léxico del engaño en la obra dramática de Lope de Vega», en La comedia de enredo. Actas de las XX Jornadas de Teatro Clásico. Almagro, julio de 1997. Murcia. 1998, pp. 97-108.
} 
ral; los pensamientos profundos condensados en pocos versos; los pasajes de gran lirismo gracias al material lingüístico; etc. Sin faltar a la ejemplificación moral en el juego dramático. $Y$ todo este arte dramático elaborado con una lengua poética que fue domeñando más y más con los años y presente ya, por ejemplo, en Amor, honor y poder ${ }^{2}$.

\section{EL AMOR Y SU ENTORNO}

El género de las comedias lo había ya fijado Lope de Vega, por lo que la aportación específica de Calderón consiste en una reelaboración estilística de la lengua. ¡Lástima que, tal vez por su desengaño vital ,nos privara de algunas reflexiones personales sobre su conjunto dramático! Desde luego, las lexías de las comedias relacionadas con el campo léxico del amor revelan la alternancia de formas tradicionales con aportaciones más originales, a veces únicas. $\mathrm{E}$ incluso semantiza novedosamente formas léxicas tradicionales ${ }^{3}$.

En esta nota observamos, en el marco del campo léxico del amor, lo que sus personajes hablan sobre sus sentimientos amorosos, en serio y en burla, para descubrir las lexías novedosas junto a formas léxicas más comunes. No diré nada sobre la cronología de las mismas, ya que no está fechado con seguridad la mayor parte del teatro profano de Calderón.

\section{FORMAS USUALES RELACIONADAS CON EL AMOR}

Calderón nos ha dejado constancia de su preocupación lingüística en diversos parlamentos poéticos de sus personajes, algo normal en un escritor de su talla. Esta característica, obligada, suele pasar inadvertida, o tiene menos importancia para algunos estudiosos más preocupados por sus innovaciones estéticas (la convergencia de varias artes en la escena), aparte de los autos sacramentales ${ }^{4}$.

2 Léase, por ejemplo, los primeros versos del caballero Teobaldo y el Rey Eduardo III de Inglaterra (O.C, tomo II, p. 70): «La esperanza en el amor / es un dorado veneno, / [...]», y la contrapuesta vivencia de Eduardo: «Basta, Teobaldo: yo creo / que es, amando, la esperanza / luz que de noche se ofrece, / [...]», o los versos de Teobaldo ante la Infanta Flérida, con quien se casará al final: «Hoy, Flérida, si pudiera / hacer lengua el corazón, / mejor mi pena dijera / si ya sus alas no son / a tantos rayos de cera; / [...]», (pp. 71-72).

3 Véase nuestro trabajo «Adiciones al tema de las citas cervantinas en Calderón: Las citas sobre Lope de Vega», en Anales Cervantinos. Madrid. CSIC.XXXV.1999, pp. 571-584.

${ }_{4}$ «[...] / La pintura, la música y poesía / de este Real obsequio fueron suaves, / dulces partes de un todo tan hermoso / como enlazar la habilidad tres artes. / [...]». Véase El Arte en la época de Calderón. Ministerio de Cultura. Dirección General de Bellas Artes, Archivos y Bibliotecas. Palacio Velázquez. Madrid. 1981, p. 15. 
Veamos algo típico del teatro de entonces: cómo manifiestan la pasión amorosa los personajes de sus comedias burguesas.

En Mañana será otro día asistimos a un monólogo desesperado de D. Fernando de Cardona cuando riñe D. ${ }^{a}$ Leonor con él:

D. FERNANDO. ¿Habrá rayo más violento, ponzoña habrá más impía, más riguroso puñal, pistola más vengativa que una palabra? No, que es rayo que centellas vibra, ponzoña que asombros vierte, puñal que el aliento quita, pistola que escupe horrores. Leonor, ¡ay Dios!, no diría lo que no supiese, no, fuera que en cosas tan vivas no es necesario que sea, pues que basta que se diga ${ }^{5}$.

Mientras en la muy conocida pieza La dama duende, el galán D. Luis de Toledo, enamorado de D. ${ }^{a}$ Beatriz, cruzarán estas palabras tan llenas de pasión:

D. LUIS.

D. ${ }^{a}$ BEATRIZ.
Como tan mal me tratáis, el idioma del desdén aprendí.

Pues ése es bien que sigáis; que en caso tal hará soledad el mal a quien le dice $\tan$ bien $^{6}$.

En su comedia Casa con dos puertas, mala es de guardar, D. Félix, hermano de doña Marcela y enamorado de su amiga D. $^{2}$ Laura, en una riña con esta, celosa en estos momentos mas con quien se casará al fin, oímos estos versos bellísimos:
D. FÉLIX.
Si no me oyes hasta el fin ...
D. ${ }^{a}$ LAURA. ¿Desto disculparte puedes?
D. FÉLIX.
Sí.

5 O.C., II. Comedias. Edición, prólogo y notas de Á. Valbuena Briones. Madrid. Aguilar. 1973, p. 781. Pistola que escupe horrores / [...] / pues que basta que se diga falta en la edición de Madrid. 1683: Séptima Parte de Comedias. 1683, folio 316. De The Comedias of Calderón. A facsimile edition prepared by D. W. Cruickshank and J.E. Varey. Tamesis Books Limited.

6 O.C., II, p. 253. También en QCL, fol. 206 v., fols. 303-304 en VSL y fol. 206 v., «1640» de VS. 


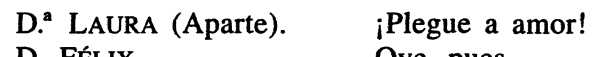

$$
\begin{aligned}
& \text { D. FÉliX. Oye, pues. } \\
& \text { D. }{ }^{a} \text { LAURA. ¿Iráste? } \\
& \text { D. FÉlIX. Sí. } \\
& \text { D. }{ }^{a} \text { LAURA. Pues dí, y vete. } \\
& \text { D. FÉlIX. Negarte que yo he querido, } \\
& \text { Laura, a Nise, fuera error; } \\
& \text { mas pensar tú que este amor } \\
& \text { es como el que te he tenido, } \\
& \text { mayor error, Laura, ha sido; } \\
& \text { pues si a Nise un tiempo amé, } \\
& \text { no fue amor, ensayo fue } \\
& \text { de amar tu luz singular, } \\
& \text { que, para saber amar } \\
& \text { D. }{ }^{a} \text { LAURA. } \quad \text { a Laura, en Nise estudié. } \\
& \begin{array}{l}
\text { A ciencias de voluntad } \\
\text { las hace el estudio agravio }
\end{array} \\
& \text { pues amor, para ser sabio } \\
& \text { no va a la Universidad; } \\
& \text { porque es de tal calidad, } \\
& \text { que tiene sus libros llenos } \\
& \text { de errores propios y ajenos; } \\
& \text { y así en su ciencia verás } \\
& \text { que los que la cursan más, } \\
& \text { son los que la saben menos? }
\end{aligned}
$$

$\mathrm{Y}$ para seguir con las comparaciones del amor con el mundo del estudio, en la misma comedia desarrollada en Ocaña, D. ${ }^{a}$ Marcela se ve obligada a hacer una visita comprometida, pues va a confesar sus cuitas amorosas a su amiga $D .^{a}$ Laura, y al revelarle la desconfianza de su hermano D. Félix (ha construido una antepuerta en su cuarto colindante con el de ella para alojar «un huésped / tan mozo, teniendo en ella / una hermana por casar»), así le explica la vorágine despertada:

$$
\begin{aligned}
& \text { [...] } \\
& \text { ¡Cuánto ignora, cuánto yerra } \\
& \text { en esta parte el honor! } \\
& \text { Que es como el que olvidar piensa } \\
& \text { una cosa, que el cuidado } \\
& \text { de olvidarla es quien la acuerda; }
\end{aligned}
$$

7 O.C., II, p. 285. Porque (por pues) en QCL, fol. 34 r., fol. 34 r. en VSL y «1640» VS, fol. 61. También hay duelo en las damas ofrece en labios de D. Fernando de Mendoza, padre de D. Félix y de D. ${ }^{a}$ Leonor, una escena muy dramática con este parlamento: «Yo no me espanto de nada. / Mozo he sido, viejo soy: / todo cabe en la edad larga. / Escuelas son de la vida / los años, en cuya sabia lacademia, la experiencia / lee, en su cátedra sentada, / aquella lición de que / se ha de ir hacia la desgracia, / antes, a que no suceda; / sucedida, a remediarla» (O.C., II, p. 1504. Tercera Parte de Comedias y Tercera... Madrid «1664» ofrecen cátredra, fol. $254 \mathrm{v}$. 


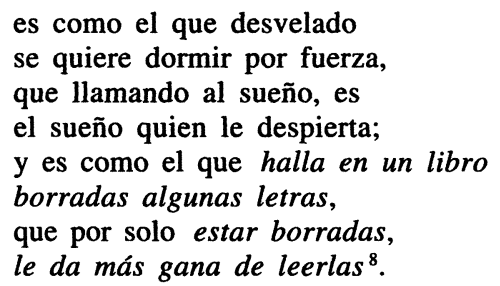

Mayor interés y complejidad hay en el pasaje siguiente de La señora y la criada, comedia de ambiente italiano. El príncipe de Parma, Crotaldo, hijo del Duque, se ensalza de buenas a primeras en una profunda discusión con la bella sobrina de su padre, D. ${ }^{a}$ Flor, quien es capaz de amar y mostrar su exquisita sensibilidad de gran dama:

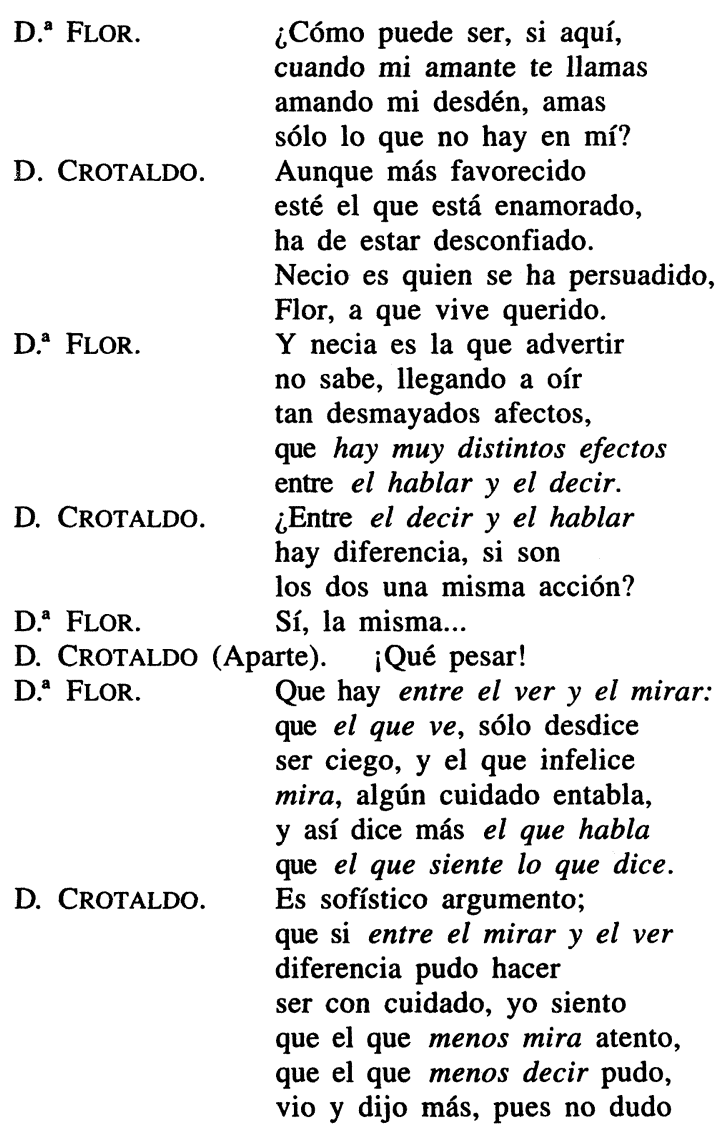

8 Los tres tomos de la Primera Parte de Comedias ofrecen el sueño (por al sueño). O.C., II, p. 287. 
ciego y mudo al amor: luego ve más el que está más ciego,

más dice el que está más mudo. Bien pudiera responder, si mi tío no viniera, y tu padre.

D. CRotaldo. Y mal pudiera yo a tu razón atender 9 .

Y sin llegar a «sofístico argumento» (¡cómo se está riendo Calderón!), D. Pedro es capaz de poetizar los afectos del amor como otros dramaturgos. Así D. César, el escondido caballero de la madrileña comedia El escondido y la tapada, en un largo parlamento con su criado Mosquito, recita:

D. CÉSAR. [...]

$$
\begin{aligned}
& \text { ¡Oh, Amor! Si te llaman dios, } \\
& \text { ¿cómo de Dios desemejas } \\
& \text { tanto, que los fingimientos, } \\
& \text { y no las verdades, premias? } \\
& \text { O deja, Amor, de ser dios } \\
& \text { o de ser ingrato deja; } \\
& \text { porque decir dios, e ingrato, } \\
& \text { o suena mal, o no suena }{ }^{10} \text {. }
\end{aligned}
$$

Mas en otro pasaje de Gustos y disgustos son no más que imaginación, el rey D. Pedro de Aragón le revela al cortesano D. Guillén su opinión sobre el amor, esta vez en los antiguos:

REY.

¿Por qué imaginas, Guillén, que los gentiles a Amor

Dios, y no rey le aclamaron, siendo así que los demás dioses, provincias verás que como reyes mandaron?

D. GUILlÉN. Nuevo ha de ser el conceto.

REY. Dile.

Pues sabrás que fue porque el amor no se ve a otro parecer sujeto. Consejos por justa ley tiene el rey; pero Dios no: y así, el Amor se llamó

9 O.C., II, p. 838. Novena Parte de Comedias, folios 111-112, ofrece las variantes: En sofístico argumento (por Es...); ciego y mudo al amor; luego (en vez de ciego y mudo es amor; luego de O.C.).

10 O.C., II, p. 676. Séptima Parte de comedias: u de ser ingrato deja (por o...), folio 521 . 


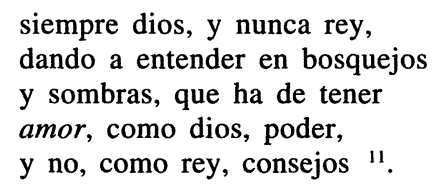

Doña Leonor de Silva, dama de No hay cosa como callar, exclama:

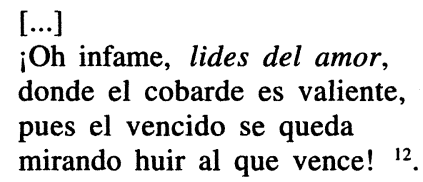

El Duque de Florencia manda a Ponleví en La banda y la flor:

Tú has de saberme todo cuanto Clori imagina: escucha el modo de descubrir el pecho de una ingrata; que como es guerra amor, ardides trata ${ }^{13}$.

En Manos blancas no ofenden la Princesa de Ursino, D. ${ }^{a}$ Serafina, en coloquio con D. Enrique Esforcia, padre de Lisarda, le oímos unir los dos temas del estudio y la guerra:

\section{$[\ldots]$}

ya que han dispuesto los cielos

que haya de ser mi favor

aquí academia de amor,

$\mathrm{y}$ allá campaña de celos ${ }^{14}$.

Y hasta describió la borrasca de celos en boca del galán D. Diego de Lara, enamorado de $\mathrm{D}^{\mathrm{a}}$ Leonor de Mendoza, al confesar aquel a D. Juan de Silva: (en Los empeños de un acaso):

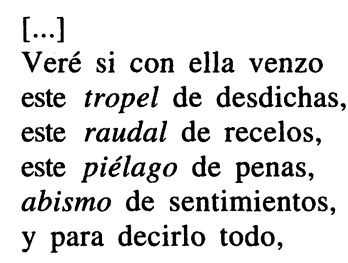

11 O.C., II, p. 971. Verdadera Quinta Parte de Comedias omite le en el verso Dios, y no rey le aclamaron, fol. 421.

12 O.C., II, p. 1014. Séptima Parte de Comedias ofrece lides de amor en vez de lides del amor, fol. 231.

13 O.C., II, p. 439. Octava Parte de Comedias, fol. 308.

14 O.C., II, p. 1111. Octava Parte de Comedias, fol. 85. 
esta borrasca de celos, que donde ellos son los más, todo lo demás es menos ${ }^{15}$.

\section{GRAMÁTICAS DE AMOR Y GRAMÁTICAS MILITARES}

Aunque estas dos formas hace pensar en un Calderón poeta del amor intelectual, hay que volver a recordar que alterna la lengua más tradicional con un registro más abstracto. Recordemos para lo primero algunos pasajes aún no señalados. En la comedia Bien vengas, mal, si vienes solo doña Ana recibe la visita de la dama y amiga $D{ }^{a}$ María, y aquella le dice:

D. aNA. Que es el rostro, oí decir, en ęl gusto o la pasión, un papel del corazón donde se suele escribir dicha pena; y si yo argüir puedo de ti alguna cosa, sin duda es pena dichosa la que tu pecho recibe, pues en tu rostro se escribe con jazmín, clavel y rosa ${ }^{16}$.

Y a doña Violante, dama de También hay duelo en las damas, en diálogo con Isabel, le oímos decir:

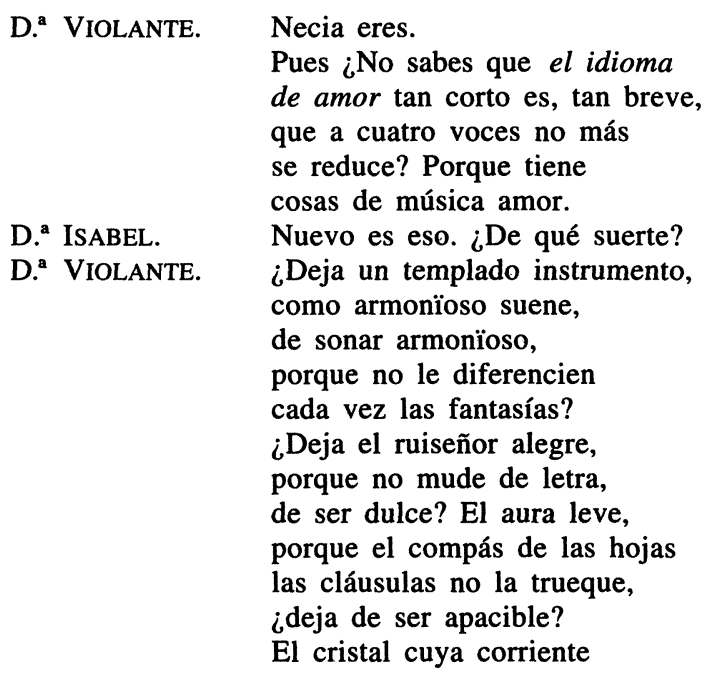

15 O.C., II, pp. 1047-48. Sexta Parte de Comedias, fol 99.

16 O.C., II, p. 606. Novena Parte de Comedias, fol. 475. 


$$
\begin{aligned}
& \text { hizo trastes de esmeralda } \\
& \text { aquella guija, aquel césped, } \\
& \text { ¿deja de correr sonoro } \\
& \text { porque continuado lleve } \\
& \text { un mismo acento? No: luego } \\
& \text { bien en metáfora puede } \\
& \text { ser de música un papel, } \\
& \text { suave, dulce, cuerdo y breve, } \\
& \text { diciendo siempre una cosa, } \\
& \text { si con ella agrada siempre, } \\
& \text { a ejemplo del instrumento, } \\
& \text { el aura, el ave y la fuente }{ }^{17} \text {. }
\end{aligned}
$$

Las dos formas señaladas, en plural, son únicas según los resultados hallados por medio del TESO y CORDE y su valor semántico está en el de 'arte'. Luego veremos qué otro autor moderno usa gramática (en singular) en sentido figurado.

Gramáticas de amor pertenece a la comedia Gustos y disgustos son no más que imaginación, al parecer representada en Valencia en el año 1638 y publicada en Octava Parte de las Comedias nuevas escogidas de los mejores ingenios de España (Madrid, 1657). Inspirada en La reina Doña María del «Fénix de los ingenios», Á. Valbuena Briones explica sus antecedentes en la edición de las Comedias de D. Pedro ${ }^{18}$.

El argumento es el siguiente: el rey D. Pedro de Aragón está casado con doña María, hija del conde de Mompeller, de donde nació el conquistador Jaime I. Sin embargo la trama amorosa surge porque D. Pedro se enamora de doña Violante de Cardona (llamada D. ${ }^{a}$ Juana en la obra de Lope), dama a su vez enamorada («mi esposa» le llama) y fiel a D. Vicente de Fox. Noble con poco patrimonio y que en la vida tiene por adversario al padre de la hermosa D. ${ }^{a}$ Violante, D. Ramón, conde de Monforte. En la jornada segunda el gracioso Chocolate, criado de D. Vicente, se introduce en la casa del Conde de Monforte para hablarle a D. ${ }^{a}$ Violante, a quien encuentra. Tras el chiste obligado con su apodo y ser de mañana («...puede / entrar cualquier chocolate / a visitar una dama»), le cuenta a la dama que su señor estuvo toda la noche paseando la calle pendiente de su seguridad, hasta que la llegada del día le ahuyentó para no ser visto por alguien de la casa. Y, como todo enamorado impaciente, le enviaba para saber cómo seguía ella e incluso hablarle si podía. He aquí los versos que interesan:

17 O.C., II, p. 1492. Tercera Parte de Comedias: la aue, el zéfiro y la fuente por el aura, el ave y la fuente, fol. 247 r. y v. Tercera Parte «1664», igual, pero con tono interrogativo el final.

18 O.C., II, pp. 955 y ss. 


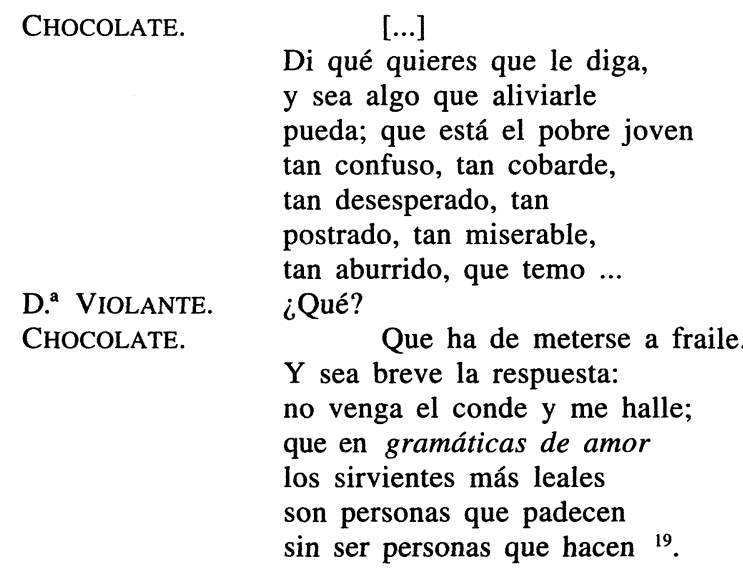

Calderón aplica la metáfora de la definición lingüística a las relaciones $\tan$ especiales que había entre señores y criados de mayor confianza. Recordemos qué recita otro gracioso, Morón, criado del caballero D. Diego, el astrólogo fracasado de la gran comedia El astrólogo fingido cuando está requebrando a Beatriz, criada de doña María de Ayala, casada al final con D. Juan de Medrano para descrédito de aquel:

BEATRIZ. Si ya no me quieres bien, bien te puedes despedir.

MORÓN. Yo tras mi amo he de ir: cuando él amare, amaré; que un criado siempre fue en la tabla del amor contrapeso del señor. Adiós ${ }^{20}$.

$\mathrm{Y}$ en El maestro de danzar hay estos versos del gracioso Chacón cuando su amo D. Enrique de Ayala se ha introducido en la casa de $\mathrm{D}^{\mathrm{a}}$ Leonor de Rocamora, requebrada por D. Juan César con los consiguientes celos de aquel. La entrada, como casi siempre, se produce al aprovechar que D. Diego de Rocamora ha salido de su casa dejando sola a la hija con la que se encuentra:

19 O.C., II, p. 972. Verdadera Quinta Parte: postrado y tan miserable (por postrado, tan miserable) y Que ha de meterse fraile (en vez de Que ha de meterse a fraile), fol. 422. También los versos del galán Octavio y la dama Lisarda en Con quien vengo, vengo, O.C., II, pp. 1139-1140.

${ }_{20}$ O.C., II, p.135. Segunda Parte de Comedias: los tres ejemplares de la edición de The Comedias traen quanto él amare, amaré en lugar de cuando él amare, amaré, fol. 209 de QC; fol. 213 de 1641 S, y 203 v. de «1637» Q. 
D. ${ }^{\mathrm{a}}$ LEONOR.

Yo te estimo

el que hayas, Enrique, vuelto.

A aquesta cuadra, que ha sido reservada, por si acaso

en casa hay huésped, te pido

te retires, y verás

si trato verdad o finjo.

D. ENRIQUe.

¡Bueno es, entrando a buscar un hombre que está escondido, ser el escondido yo!

CHACón.

Esos son los solecismos

de amor, en persona que hace

y padece a un tiempo mismo ${ }^{21}$

Calderón, por su estilo tan reflexivo, a veces presenta el uso de formas lingüísticas del mismo campo léxico en otros pasajes. Así en la comedia El galán fantasma hay versos que recuerdan al pasaje comentado de Gustos y disgustos son no más que imaginación. Están en la jornada primera cuando la enamorada Julia cita a su caballero Astolfo para prevenirle del peligro surgido contra él al haberse fijado en ella el Duque de Sajonia, Federico. He aquí el pasaje:

JULIA. $\quad$ Oye, y sabrás lo que pasa.

[...]

Viento en popa nuestro amor navegaba hermosos mares de rayos y de matices, quieto el golfo y manso el aire.

[...]

El gran Duque Federico de Sajonia, que Dios guarde, (o que no le guarde Dios, si ha de ser para quitarme mi media vida en la tuya), acaso me vio una tarde que al prado a verte salí: barbarismo de amor grande, salir a ver y ser vista; pues, mal gramático, sabe persona hacer que padece de la persona que hace ${ }^{22}$.

21 O.C., II, p. 1565. Tercera Parte de Comedias: de amor, dar persona que haze (por de amor, en persona que hace) y en el verso siguiente: y padeze vn caso mismo (en lugar de y padece a un tiempo mismo), fol. 42 v. (igual lecturas en «1664»).

${ }^{22}$ O.C., pp. 637-38. Los tres ejemplares (1637 QC, $1641 \mathrm{~S}$ y '1637' Q) de la Segunda parte de Comedias, de D. W. Cruickshank y J.E. Varey, ofrecen la variante mar por prado, mientras sí aparece esta segunda en la edición de Vera Tassis de 1726. 
En cuanto a gramáticas militares la escribió Calderón en el drama (no es, pues, una comedia burguesa) Las armas de la hermosura. El joven galán romano Coroliano es quien lo dice en el parlamento con los ancianos Aurelio y Flavio, cuando estos le indican que se dirija al Senado para que en pública aclamación le concedan «la bengala, estoque, toga y diadema / de general de sus armas». He aquí los versos:

\begin{tabular}{|c|c|}
\hline $\begin{array}{l}\text { COROLIANO. } \\
\text { AURELIO Y FLAVIO. } \\
\text { COROLIANO. }\end{array}$ & $\begin{array}{l}\text { Más me ha de dar. } \\
\text { ¿Qué es? } \\
\text { Licencia }\end{array}$ \\
\hline & $\begin{array}{l}\text { de que responda a Sabinio } \\
\text { y al mote de sus banderas, } \\
\text { poniendo yo en las de Roma } \\
\text { el mismo. }\end{array}$ \\
\hline ToDOs. & ¿De qué manera? \\
\hline COROLIANO. & $\begin{array}{l}\text { S. P. Q. y R. son } \\
\text { cuatro letras que interpretan } \\
\text { al Sabino Pueblo. ¿Quién } \\
\text { resistirá? Y con las mismas } \\
\text { a su arrogante pregunta } \\
\text { han de responder las nuestras, } \\
\text { para que conozca el mundo } \\
\text { cuán en un caso concuerdan } \\
\text { gramáticas militares } \\
\text { la pregunta y la respuesta; } \\
\text { pues si S. P. Q. y R. } \\
\text { ¿Quién Piensa Que hay Resistencia } \\
\text { al Sabino Pueblo?, dicen, } \\
\text { también dirán a quien lea } \\
\text { en nuestro favor el mote } \\
\text { de sus mismas cuatro letras, } \\
\text { Senado y Pueblo romano } \\
\text { es Quien Resistirle Piensa! }\end{array}$ \\
\hline $\begin{array}{l}\text { FLAVIO. } \\
\text { UNOS (dentro). }\end{array}$ & $\begin{array}{l}\text { ¡Bien lo has pensado! } \\
\text { ¡Armas, armas! }{ }^{23}\end{array}$ \\
\hline
\end{tabular}

El pasaje es bélico (gramáticas militares equivale a 'reglas militares', de donde la conexión con 'arte'), pero el tema del amor y la contienda por él está extendido a lo largo de la Literatura. En la comedia Lances de amor y fortuna, cuya acción se sitúa en Barcelona, hay una muestra espléndida de metáforas relacionadas con el mundo del dios Marte, en boca del Conde de Urgel, Lotario. Es en la escena lírico-dramática del asedio vano a Aurora, Condesa de Barcelona, enfrentada políticamente a su hermana Estela:

23 O.C., Dramas. Edición de Luis Astrana Marín. Madrid. Aguilar. 1941, pp. 53536. Novena Parte de Comedias: Quién piensa hazer Resistencia (por ¿Quién Piensa Que hay Resistencia), fols. 7-8. 
LOTARIO (Aparte).

(El son me ciega

si la miro: hermosa es).

Hoy a esos invictos pies
un nuevo soldado llega,

que a vuestro servicio entrega

un escuadrón de soldados,

donde vienen alistados,

para amaros y serviros

lágrimas, penas, suspiros,

pensamientos y cuidados.

Por capitán viene amor

resuelto a cualquier daño, y por cabo el desengaño, cabo y fin de su rigor; por artillero mayor el corazón, porque luego que os mira, turbado y ciego, rayos a los vientos da; ¿qué muchos si en él está toda la esfera del fuego? Luego os vienen a servir de centinelas mis ojos: bien que mis penas y enojos no les dejarán dormir, ellos sabrán resistir sueño a la noche y al día; y para perdida espía viene mi loca esperanza, que bien este nombre alcanza mi esperanza por ser mía. Para hacer minas, también conmigo vienen los celos, porque siempre sus desvelos lo más escondido ven: ingenieros son, a quien ninguna máquina yerra, pues en la amorosa guerra saca a luz su resplandor estratagemas de amor de debajo de la tierra. Esto os ofrezco, y después mi vida, Aurora, entre tantas; que es bien sirva a vuestras plantas vida que tan vuestra es.

Todo se ofrece a esos pies; triunfad, y vuestra persona digna de mayor corona, la imperial ceñida vez, porque todo el mundo sea de quien es hoy Barcelona ${ }^{24}$.

24 O.C., II, p. 171. Primera Parte de Comedias, QCL, fols. 173 v. 174 r.; VSL, fols. 306-307 y «1640» VS, fols. 173 v.-174 r., ofrecen las variantes siguientes: re- 
La respuesta de Aurora no es favorable para el caballero: «Invicto Conde Urgel, / cuya heroica frente viva, ya coronada de oliva, / ya ceñida de laurel, / [...] / no sé si estoy obligada, / no sé si estoy ofendida»:

\title{
LA ESPIRITUALIDAD DE UNAMUNO FRENTE AL ARTE CALDERONIANO
}

Hay otro gran escritor noventayochista, D. Miguel, que en una de las poesías de su Cancionero escribe en singular el lexema. Se trata de una creación de discurso poético con un sentido semántico distinto y a tono con su pensamiento filosófico. El poema, compuesto de dos cuartetas, es el siguiente:

\author{
Gramática del paisaje, \\ la que al alma le conjuga \\ con el campo al ir de viaje; \\ de viaje no, que de fuga! \\ Sentir la naturaleza \\ no es cosa de analfabetos; \\ se la siente en la cabeza \\ cuando se está en sus secretos ${ }^{25}$.
}

Se da la circunstancia que en la poesía anterior del Cancionero, la 1529, Unamuno usa el valor técnico de gramática (gramática del Brocense) y cuyo poema íntegro reproducimos en nota ${ }^{26}$.

En Gramática del paisaje su autor espiritualiza a la naturaleza al vivificarla por la proyección de su yo. Se trata de un caso más de la sub-

suelto a qualquiera daño (por resuelto a cualquier daño); qué mucho si en él está (por ¿qué muchos si en él está); no los dejarán dormir (en vez de no les dejarán dormir) y sueño a la noche y el día (por sueño a la noche y al día).

También puede leerse, de la comedia de ambiente italiano La banda y la flor, los parlamentos de D. Enrique y la dama Lísida al principio de la jornada segunda, donde aquel apela al astuto cazador, al marinero ingenioso, al capitán y a la mina, para atraerse a la enojada Lísida, celosa por las relaciones del galán con su hermana Clori.

25 Miguel de Unamuno, Poesía Completa. Prólogo de Ana Suárez Miramón. Madrid. Alianza Editorial. 1987-89, 4 tomos. El Cancionero. Diario poético (1928-1936) está en el tercero, $782 \mathrm{pp}$. y el poema 1530 está fechado el 18 de agosto de 1930. Lleva la cita de un verso de la obra De Rervm Natvra, II-14: «o pectora caeca», cuyo verso completo es: «O miseras hominum mentis, o pectora caeca!» ( «iOh míseras mentes humanas! ¡Oh ciegos corazones!»).

26 «Salamanca, Salamanca, / renaciente maravilla, / académica palanca / de mi visión de Castilla. / Oro en sillares de soto / de las riberas del Tormes; / de viejo saber remoto / guardas recuerdos conformes. / Hechizo salmanticense / de pedantesca dulzura; / gramática del Brocense, / florón de literatura. / Ay mi Castilla latina / con raíz gramatical, / ay tierra que se declina / por luz sobrenatural!», y lleva la fecha del día anterior a Gramática del paisaje. 
jetividad de su pensamiento filosófico, que proyecta a la creación terrenal su ansia de Dios en la creación literaria. Y no es nada casual, dadas las numerosas pruebas de las lecturas de los clásicos. Temas como el sueño de la vida, la cueva, la imagen del agua como espejo de la vida que pasa, etc., hace pensar en una creación personal muy alejada del sentido artístico calderoniano, pero retomada y recreada en la poesía existencialista del vasco. Este otro poema es uno de tantos en el que recrea D. Miguel temas barrocos:

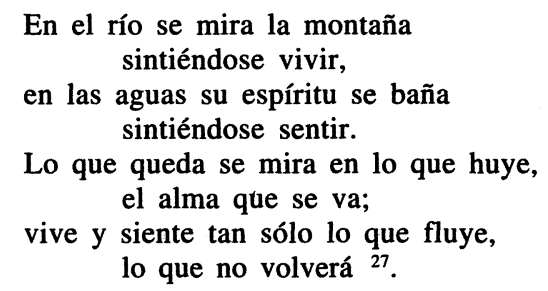

\section{RECAPITULACIÓN}

Como me ha ocurrido con calas anteriores, al examinar el léxico calderoniano, se confirma que el autor madrileño alterna formas tradicionales con innovaciones en su lengua poética. En un tema tan universal como el amoroso, Calderón hace decir a distintos personajes qué es el amor, cómo lo sienten y conciben según su rango social. Crea lexías en el nivel del discurso poético como gramáticas de amor y gramáticas militares, expresiones que connotan su acusado talante intelectual (otros dramaturgos son más líricos). La primera, escrita para la comedia Gustos y disgustos son no más que imaginación, gira en torno al amor concebido como 'arte'. Incluso por su estilo tan reflexivo, a veces presenta el uso de formas lingüísticas del mismo campo léxico en otros pasajes. Mientras la segunda citada, empleada en el drama Las armas de la hermosura, alude a la concepción de las reglas militares como 'arte' también (en plural por no ser único el principio), y enlaza con las metáforas construidas con léxico militar, al concebir el amor a veces como lucha: el asedio a quien se pretende conquistar.

(Miguel de Unamuno, lector de clásicos, en el poema 1530 de su Can-

27 Cancionero (III, número 273 de la edición citada). Por señalar otros poemas recogiendo influencias de Calderón se pueden señalar de El Cristo de Velázquez (1920) el titulado «La vida es sueño» (I, X, pp. 362-63); el LXXXV en De Fuerteventura a París. Diario íntimo de confinamiento y destierro vertido en sonetos (1925) (II, p. 334); el soneto CVIII «En la caverna de la vida oscura / ... / sin fin linaje que hace de Dios cosa» (IV, p. 185), o el poema titulado «Repetición» (IV, pp. 151-52); etc. 
cionero, escrito en agosto de 1930, usa gramática del paisaje, en singular, en una composición donde espiritualiza el paisaje según su concepción intelectual). La diferencia semántica entre Calderón y Unamuno se refleja en el uso del plural frente al singular. Existe también contraste de las épocas en que vive cada escritor, Calderón, archiespejo del Barroco como Velázquez, presenta así de modo reflejo su oficio de escritor en los siguientes versos, recitados nada menos que por una de las damas de No siempre lo peor es cierto:

[Sala en casa de D. Juan Roca, galán].

D. ${ }^{\text {a }}$ BEATRIZ, leyendo un papel; tras ella, Inés.

INÉS (Aparte).

BEATRIZ.

Leyendo mi ama un papel,

tan triste y confusa está,

que mil deseos me da

de saber lo que hay en él.

Una vez le aja furiosa,

y al Cielo elevada mira;

otra llora, otra suspira.

INÉS (Aparte).

¿Hay suerte más rigurosa?

A leer vuelve. ¿De qué nace

ya el agrado y ya el furor?

Sin duda que es borrador

de alguna comedia que hace.

D. a BeAtriz. Bien dicen que una cruel

pluma áspid es de ira lleno, de quien la tinta es veneno

en las hojas del papel.

Dígalo yo, pues a mí

muerte su traición me dio.

¿Quién creerá mis penas?

INÉS.

$$
\text { Yo }{ }^{28} \text {. }
$$

28 O.C., II, pp. 1458-59. Octava Parte de Comedias, fol. 164. El verso de D.a Beatriz lo señala en tono exclamativo: ¡Hay suerte más rigurosa! 